\title{
APPRAISAL IN THE MEANING OF A NEW WORD
}

\author{
(c) 2019 Martynova Irina Anatolevna \\ Candidate of Philology, Associate Professor \\ (C) 2019 Belyakova Olga Vladimirovna \\ Candidate of Philology, Associate Professor \\ Samara State University of Economics \\ E-mail: miasseu9@gmail.com
}

Keywords: cognitive mechanism, vagueness, semantic meaning, appraisal

The article presents an analysis of the appraisal component in the meaning of the -ish lexeme that recently has been conventionalized in English. It was found that the use of the linguistic unit under study indicates the work of a complex cognitive mechanism. Based on the comments of native speakers the data were analyzed. A whole range of shades of meanings was identified with which the ish operator corrects the semantics of the statement.

УДК 81'44

Код РИНЦ 16.00.00

\section{НЕКОТОРЫЕ АСПЕКТЫ ОЦЕНКИ КАЧЕСТВА НАУЧНО-ТЕХНИЧЕСКОГО ПЕРЕВОДА}

\author{
(C) 2019 Никитина Ирина Николаевна \\ кандидат филологических наук, доцент \\ Самарский государственный экономический университет \\ E-mail: i.n.nikitina@gmail.com
}

Ключевые слова: научно-технический перевод, адекватность перевода, виды информации, уровни эквивалентности перевода, оценка качества перевода.

Статья посвящена анализу таких понятий, как адекватность перевода, виды информации, уровни эквивалентности перевода, которые напрямую оказывают влияние на оценку качества перевода. Рассматривая данные понятия применительно к научно-техническому переводу, автор описывает общие принципы оценки его качества.

Предшествующее столетие, и особенно вторая половина XX века, знаменательны тем, что превратили науку и технологии в главный источник, с одной стороны, и цель международного научного общения, с другой. Тот факт, что больше половины всех научных разработок и изысканий в области техники и высоких технологий становятся известными специалистам и интересующейся публике посредством английского языка, делает его средой и средством осуществления научных дискуссий, решения насущных проблем современных технологий.

Подобная лингвистическая экспансия является прежде всего экспансией терминов, т.е. позволяет предположить существование особого языка, точно отвечающего требованиям общения в области науки, техники и технологии. Как известно, научная и техническая информация 
должна быть точной, полной и объективной для достоверного представления наблюдаемых фактов иди сделанных выводов.

Практика научно-технического перевода показывает, что научно-технический перевод осуществляется по слдующей схеме: уяснение смысла оригинала на основе общего контекста и широкой базовой экстралингвистической информации; интерпретация с учетом стилистических и терминологических стандартов.

Достичь высокого качества научно-технического перевода можно только при условии правильной передачи научных или технических фрактов оригинала.

Язык, на котором передается подобная информация, должен оперировать точными, строго однозначными словарными единицами, которые не препятствовали бы пониманию и восприятию информации. Словарные единицы в языке научного общения должны быть чётко определены как физические величины и описаны в терминах пространственно-временных отношений. Прагматический аспект считается ведущим при научно-техническом общении и может рассматриваться как прагматическая основа выбора грамматических, семантических или синтаксических средств.

Подобные особенности научно-технического текста должны быть учтены при переводе. Перевод-это транссрормирование некоего содержательного момента из структур исходного языка в структуры языка перевода с целью сделать его доступным для третьих лиц1. Таким образом, задача любого переводчика заключается прежде всего в том, чтобы сделать предметом своей мысли, а затем и других то, что исторически, идеологически, и технологически может быть далеко от собственной технологической культуры переводчика. Это означает, что для понимания и дальнейших операций с конкретным содержательным моментом, т.е. для осуществления самой процедуры перевода, необходимо рассмотрение объекта перевода в его целостности, в совокупности его связей, как непосредственных, так и опосредованных в контексте "эпохи" существования объекта, а также его предыстории и возможного будущего. Правильному переводу может воспрепятствовать большая активность переводчика, что затрудняет его вживание в объект перевода. Очевидно, что наиболее оптимальным вариантом, при котором может быть достигнут успех, является соотнесённость "эпох" переводчика и объекта перевода или конкретной единицы перевода. При этом необходимо учитывать некоторые моменты.

1) Согласно русской филологической традиции слово предполагает наличие комплекса признаков, что свидетельствует о его устойчивости и единстве.

2) Термин рассматривается с точки зрения соотношения целого и части. Именно цельность, интегративность позволяют рассматривать объект как устойчиво существующий.

3). Принцип соотношения целого и части реализуется категорией интеграционной статики и категорией иерархических построений.

Таким образом, учет всех вышеуказанных моментов и особенностей научно-технических текстов неизбежно ведет к терминологически верному переводу.

Оценка результатов перевода представляет интерес для преподавателей особенно при обучении переводу оригинальной научной литературы по специальности. Любая качественная оценка перевода подразумевает его оценку по отношению к какой-то норме. Необходимы определенные нормативные требования, соответствие которым делает перевод правильным.

Известно, что перевод одновременно ориентирован на содержание и жанровостилистические особенности оригинала, на норму и узус языка перевода и на прагматические требования конкретного переводческого акта. Полнота передачи содержания оригинала в пере- 
воде зависит от соотношения языковых средств исходного языка и переводящего языка, вследствие чего норма эквивалентности определяется собственно языковыми факторами. "Правильный" перевод может осуществляться на разных уровнях эквивалентности. На высшем уровне воспроизводятся все элементы содержания оригинала. На низшем уровне эквивалентности передается лишь основная часть содержания оригинала, его основная коммуникативная функция. Немаловажную роль при оценке качества перевода играет также оценка воспроизведения стилистических особенностей того типа текста, к которому принадлежит оригинал, иначе говоря, соблюдение жанрово-стилистической нормы перевода информативного текста, где доминантой оказывается функция сообщения каких-либо фактических данных.

Для конкретного перевода нетрудно выявить, какой аспект нормы будет доминировать: эквивалентность или прагматика. Что касается жанрово-стилистической нормы и нормы переводческой (переводящего языка), то они являются оптимальными требованиями ко всем видам научно-технического перевода

Оценка результатов перевода неразрывно связана с такими понятиями, как "адекватность перевода" и "виды информации". Ситуационные условия деятельности переводчика предъявляют различные требования к полноте и точности перевода. Поэтому понятие "адекватность перевода" имеет разное содержание в зависимости от вида перевода. Определение этого понятия как воссоздание единства формы и содержания оригинального сообщения средствами другого языка применимо в полной мере только к переводу художественных произведений. В отношении письменного перевода информативных текстов: научной, газетной и журнальной публицистики, деловой документации, коммуникативную ценность представляет прежде всего содержательная информация. Адекватный перевод в этом случае - точная и полная передача содержательной информации².

Содержательная информация также может иметь различную коммуникативную ценность для адресата. Целесообразно различать три вида содержательной информации по степени коммуникативной ценности: 1) ключевую информацию, 2) второстепенную информацию, 3) нулевую информацию.

Безусловно, понятие "адекватность перевода" - величина не абсолютная, а относительная. Она предполагает воспроизведение на языке транслята семантической, структурной и прагматической информации в таком их соотношении и объеме, которые требуются по условиям осуществления деятельности. Поэтому к оценке переводческих умений необходимо подходить дифференцированно в зависимости от вида перевода ${ }^{3}$ Оценивая последовательный перевод и перевод с листа, мы учитываем отношение правильно переданных единиц ключевой информации к общему количеству этих единиц в тексте. При письменном переводе информативного текста оцениваем соотношение суммы правильно переданных единиц ключевой и второстепенной информации и их общего количества в тексте. Перевод нулевой информации не учитывается в любом виде перевода информативных текстов. При оценке умений двустороннего перевода можно оценивать адекватность передачи содержания каждой отдельной речевой задачи в условных единицах. Например, точная передача - 2 единицы; не совсем точная, с частичным искажением - 1 единица; полное несоответствие - 0 единиц. Общая оценка перевода выразится в отношении суммы полученных единиц к ожидаемой сумме за все высказывания. Например, требуется перевести пять фраз, за которые переводчик в идеале должен получить 10 единиц. На самом деле, некоторые фразы были переданы не совсем точно, и переводчик в 
сумме набрал 8 единиц, что соответствует по нормам оценке "хорошо". Данный подход позволяет дать колличественную оценку качества перевода.

1 Швейцер АД. Теория перевода: Статус, проблемы, аспекты. М.: Наука, 1988. 215 с.

2 Комиссаров В.Н. Общая теория перевода (лингвистические аспекты): Учеб. для ин-тов и фак. иностр. яз. М.: Высш. шк., 1990. 253 с.

3 Никитина И.Н. Английский язык. учебное пособие по двустороннему переводу текстов по экономике и бизнесу. Самара, 2011. 219 с.

\title{
SOME ASPECTS OF QUALITY ASSESSMENT OF SCIENTIFIC AND TECHNICAL TRANSLATION
}

\author{
(C) 2019 Nikitina Irina Nikolaevna \\ Candidate of Philological Sciences, Associate Professor \\ Samara State University of Economics \\ E-mail: i.n.nikitina@gmail.com
}

Keywords: scientific and technical translation, translation adequacy, types of information, the level of translation equivalence, translation quality assessment.

The article is devoted to the analysis of such concepts as translation adequacy, types of information, the level of translation equivalence, which directly affect the assessment of the quality of the translation. Considering these concepts in relation to scientific and technical translation, the author describes the general principles for assessing its quality.

УДК 8

Код РИНЦ 16.21.33

\section{СИНТАКСИЧЕСКИ НЕЗАВЕРШЕННЫЕ ВЫСКАЗЫВАНИЯ В РАЗГОВОРНОЙ И ПИСЬМЕННОЙ РЕЧИ НЕМЕЦКОГО ЯЗЫКА}

\author{
(c) 2019 Перцевой Антон Юрьевич \\ Центр профессиональной переподготовки \\ Самарский государственный технический университет \\ (C) 2019 Перцевая Екатерина Александровна \\ кандидат филологических наук, доцент \\ Самарский государственный экономический университет \\ E-mail: apertsevoi@hotmail.com, kmilyutina@mail.ru
}

Ключевые слова: незаконченные синтаксические конструкции, неполное предложение, неразвернутые предложения, незаконченные структуры. 